Europe's Journal of Psychology 1/2010, pp. 1-5

www.ejop.org

\title{
Kicking the can of stigma down the road
}

\author{
By Tony Foster, M.Ed., L.P.C.- I \\ Center Director, Amarillo Mental Health Consumers
}

As I strolled through the vestibule of memories past, I witnessed the unfolding of hell's fire. The caterwauling of the desperate and disarmed provided the shadowy overcast as a young man of stealthy step and demoniacal eyes lay hold of a 45 caliber pistol, and with superior marksmanship, picked off the pristine, one by one. What bedeviled such a man that he could, without compassion or bereft of charity, take aim at his own, and with calculated thievery, deprive a man/woman of his last breath?

These acts of macabre have disquieted many souls who unwelcome the idea of an untidy universe. In trying to explain, "the carousal of the disorderly" some say that the collegiate genocide of Seung-Hui Cho was the bloodlust reveling of a madman unhinged from reality. Blistered across the front page of the San Antonio Express News, a young female named Otty Sanchez cannibalized her $3 \frac{1}{2}$ week old child. So hideous was the crime that the respondent police officers and collateral emergency personnel had to receive aftercare and trauma counseling. The news article implied psychosis and possible untreated schizophrenia as the culprit of the unthinkable.

Such helter-skelter has become the media's primetime fodder with the leitmotif being those with a psychiatric history are the major perpetrators of violent crime. The propaganda machine fires off daily reports characterizing the mentally ill as a motley crew of impulsives who cannot control their primitive urges. The number of opinion-spun news sources is legion, and furor seems to supersede facts. Such demagoguing has led the majority of Americans to believe the a priori assumption that mental illness and violence are inextricably linked. Are the media's assertions apodictic? Does the sensationalism that is often dealt out to the mentally ill pass the scientific litmus test? 
In an attempt to resuscitate the victims of primetime smothering one must breathe in the oxygen of scientific research as a counterbalance. A fit measure of mental illness and violence would be forcible rape. Nobody, foolishly doubts, that rape is a violent act. In fact, Judith Rabkin, of John Hopkins University investigated similar concerns. In a breakthrough study, Rabkin, wanted to uncover the antecedents that led a person to commit rape (Rabkin, 1979). Her idea was to administer a psychosocial history of each rapist in the Continental United States. She, later, studied historical triggers, psychiatric intervention, protean ethnicities, and socio-economic status in an effort to compartmentalize the demographics into a rapist's profile. For our purposes, only $5 \%$ of the rapists had a psychiatric history (Rabkin, 1979). The former percentage is more compelling when you couple it with the fact that $25 \%$ of Americans suffered from a diagnosable mental illness in 1978 (Commission on Mental Health, 1978). Roughly, $25 \%$ of the population had a potential diagnosis, but they were only causing $5 \%$ of the problem. Admittedly, Rabkin's study is old, but newer research such as Diana Scully's study of convicted rapists yielded similar and slightly higher results. Among the sample of convicted rapists she studied, $26 \%$ had a history of psychiatric outpatient and inpatient visits (Scully, 1994). Donning are scientific caps leads us to believe that since the mentally ill comprise $26.2 \%$ of the population, it hardly seems noteworthy to mention they are causing $26 \%$ of the epidemic (NIMH, 2009). That is within the norm of any subgroup.

Now let's statistically flip the script. Seventy four to $95 \%$ of those examined did not have a diagnosis and committed forcible rape. This is unnerving to many because the media has taught us that psychopathology is implicated in most violent encounters. Some may find it more savory to swallow a mouthful of tacks than admit to the fact that a person without a diagnosis could do such a thing. Most experts concede that rapists are your "adolescents next door"; they are family members, and can be those highly esteemed in the community bartering their way through the courts (Scully, 1994).

Despite research, the media locomotive hijacks Internet threads and other mediums of information delivery, clenching their fists at those hell-bent personalities whom they say need to be locked up. It's time for mental health advocates to assist others in taking a moral pulse and discovering what palpitations of deceit exist. In 1998, Monhan et al. released the well-known MacArthur Foundation study that graced the front page of Time News and several other periodicals. Consistent with the scientific method, Monahan and his colleagues culled a stratified random sample of 500 people in the Pittsburgh municipality. Inpatients who had been released due to remission of symptomology were compared to the random sample of 500 citizens in 
Pittsburgh for levels of community violence (Monahan et al., 1998). The risk assessment tool included 10-week interviews with family members, friends, collaterals, and an in-depth perusing of police records. Hits, aggressive posturing, and criminal acts were some of the measures included in the tally (Monahan et al., 1998).

Perhaps, a re-tread for some, but elucidating to others, the results of the MacArthur Foundation study found no statistically significant difference in levels of violence between mental health patients, recently released from the hospital, and those living in the same community. There was, however, a significant difference in those mentally ill who abused substances and those undiagnosed who abused substances (Monahan et al., 1998). Apparently, alcohol and back alley drugs affect the cerebral inhibitor of the brain, which reigns in violent behavior. Those who have a mental illness are more susceptible to this unfettered neurochemical reaction, and levels of aggression are higher. Nevertheless, substance abuse alone is a more reliable corollary of knee-jerk brutality than mental illness (Monahan et al., 1998).

A moderate number of studies focus on individuals convicted of homicide. In the British Journal of Psychiatry, Shaw et. al., 2006, conducted a survey of 1,594 convicted murderers incarcerated in England and Wales. Among the 1,594 felons, $34 \%$ had a history of mental illness and 5\% had chronic schizophrenia (much higher percentages). Other prison studies yield similarities. The methodological flaw of prison studies is the sampling pool they draw from ceases to be random and stratified for generalization purposes. This cherry picking of homicide-only felons gives us a reliable cohort measurement, but in no way can it be extrapolated to the global population of the mentally ill. The criminal justice system is not the only domain where those with schizophrenia, depression, and bi-polar disorder reside. In addition, many studies rely on Pearson's Product-Moment correlation to determine a relationship between mental health and violence; however, causation can never be ascertained. The direction of causation and other confounding variables make scientific certainty elusive.

New research from Duke University highlights the victimization of the mentally ill. People with bi-polar disorder, schizophrenia, and depression are $21 / 2$ times more likely to be raped, mugged, and physically assailed (Hiday et al., 1999). Choe et. al., 2008 reviewed 10 studies of violent victimization and discovered that $35 \%$ of those in the meta-analysis were mentally ill and recipients of such mayhem. The odds of being killed by a stranger with psychosis is roughly, 1 in 10,000,000 (Szmukler, 2000). 
Despite empirical research, the stereotypes persist in the guise of legitimate news. According to the President's New Freedom Commission On Mental Health, 61\% of Americans believe those with schizophrenia are likely to be dangerous (NFC, 2003). Sixty four percent of co-workers do not want someone with schizophrenia in close proximity to them (Pescosolido, et al., 1999). Television dramas portray the mentally ill as "caricatures that are out of their tree" and prone to spontaneous violence $75 \%$ of the time (3 1/2 times the average rate) (Shain and Phillips 1991). Why have people not disavowed themselves from the obvious disingenuousness? Is the smelling salt of truth too hard to breathe in?

Kicking the can of stigma further down the road will not help. Advocacy agencies should be involved in literature, commercials, and other venues of information delivery that obliterate such thinking and shade those affected by mental illness in a more favorable hue. Most of us who have mental illness are not saying that we are incapable of violence. We just implore the media to employ responsible journalism and spread the margarine of culpability across the board evenly. Violence is a pandemic that affects us all. Yet there will be some that are satisfied with the divide of the deranged.

\section{References:}

Choe, J.Y. Teplin L.A., \& Abram K.L. (2008). Perpetration of Violence, Violent Victimization, and Severe Mental Illness: Balancing Public Health Concerns. Psychiatric Services, Feb 2008; 59: 153 -164.

Hiday, V.A., Swartz, M.S., Swanson, J.W., (1999). Criminal victimization of persons with severe mental illness. Psychiatric Services, 50, 62-68.

Monahan, J., Steadman, H., Mulvey, E., Robbins, P., Appelbaum, P., Grisso, T., Roth, L., \& Silver, E. (1998). Violence by people discharged from acute psychiatric inpatient facilities and by others in the same neighborhoods. Archives of General Psychiatry, 55, 393-401.

National Institute of Mental Health (2009). Statistics. Retrieved from http://www.nimh.nih.gov/health/topics/statistics/index.shtml

New Freedom Commission on Mental Health, (2003). Achieving the Promise: Transforming Mental Health Care in America. Final Report. DHHS Pub. No. SMA-03-3832. Rockville, MD 
Pescosolido, B.A., Monahan, J. Link, B.G. Stueve, A., \& Kikuzawa, S. (1999). The public's view of the competence, dangerousness, and need for legal coercion of persons with mental health problems. American Journal of Public Health, 89, 1339-1345.

Peters, J.T. \& Wooley G. (1978). Presidential Commission on Mental Health Report. Santa Barbara, CA: University of California.

Rabkin, G.J. (1979). The epidemiology of forcible rape. American Journal of Orthopsychiatry, 49(4), 634-646.

Scully. D. (1994). Understanding sexual violence: a study of convicted rapists. New York: Harper Collins.

Shain, R.E., \& Phillips, J. (1991). The stigma of mental illness: Labeling and stereotyping in the news. In: Wilkins, L., and Patterson, P., eds. Risky Business: Communicating Issues of Science, Risk, and Public Policy. New York, NY: Greenwood Press. pp. 61-74.

Shaw J, Hunt IM, Flynn S, Meehan J, Robinson J, Bickley H, Parsons R, McCann K, Burns J, Amos T, Kapur N, Appleby L. (2006). Rates of mental disorder in people convicted of homicide. National clinical survey. The British Journal of Psychiatry, 2006 Feb, 188:143-7.

Szmukler, G. (2000). "Homicide enquiries: what sense do they make?" Psychiatric Bulletin 24: pp.6-10

About the author:

Tony Foster secured his BA in Psychology, and two years later, received his M.Ed. in Counseling from Sul Ross State University. He is currently Assistant Director of Amarillo Mental Health Consumers, a peer-driven center, based on the substrate that recovery from mental illness is possible. His responsibilities include advocacy, individual counseling, wellness programming, peer-led groups, and instructing psychology classes. Tony is also a licensed professional counselor Intern working towards full licensure in 2010. His research interests include psychopathology, theories of personality, statistical analysis and elements of social psychology.

E-mail address: AMHCamarillo@gmail.com 